\title{
A Wide Variation in Diagnostic and Therapeutic Strategies in Chronic Pancreatitis: A Dutch National Survey
}

\author{
Aura AJ van Esch ${ }^{1}$, Usama Ahmed $\mathrm{Ali}^{3}$, Harry van Goor ${ }^{2}$, Marco J Bruno ${ }^{4}$, J oost PH Drenth ${ }^{1}$
}

Departments of ${ }^{1}$ Gastroenterology and Hepatology and ${ }^{2}$ Surgery, Radboud University Nijmegen Medical Center. Nijmegen, The Netherlands. ${ }^{3}$ Department of Surgery, Dutch Pancreatitis Study Group, University Medical Center Utrecht. Utrecht, The Netherlands. ${ }^{4}$ Department of Gastroenterology and Hepatology, Erasmus University Medical Center.

Rotterdam, The Netherlands

\begin{abstract}
Context Optimal diagnostic and treatment modalities in chronic pancreatitis are controversial due to lack of evidence. Objective To evaluate current clinical practice, we conducted a survey with the primary objective to evaluate decisions regarding the diagnosis, management and screening in chronic pancreatitis. Design We developed a vignette survey. Setting We surveyed Dutch gastroenterologists, internists, gastrointestinal surgeons and an international expert panel. Results A total of 110 questionnaires ( $31 \%$ gastroenterologists, $39 \%$ internists and $20 \%$ gastrointestinal surgeons) were returned out of the 1,324 sent (response $8.3 \%$ ). There was a wide variation in strategies regarding diagnosis, treatment and screening in chronic pancreatitis. As a diagnostic test, serum amylase is used frequently by internists, while gastroenterologists and experts often use fecal elastase. Most respondents preferred CT-scanning for diagnosis, while experts preferred transabdominal ultrasonography as an initial test. Respondents frequently use pancreatic enzymes for treatment of pain in chronic pancreatitis. The majority advised to perform an intervention (endoscopic or surgical) in case of morphological changes of the pancreatic duct. Conclusions The results of our survey identify important differences between physicians in diagnosis and management of chronic pancreatitis. This is often due to lack of evidence and consensus in literature. Certain wide-spread practices are in contrast with available evidence, and should be addressed by improved education and adherence to guidelines.
\end{abstract}

\section{NTRODUCTI ON}

There are a number of challenges when it comes to the diagnosis and treatment of chronic pancreatitis. The diagnosis of chronic pancreatitis depends on interpretation of a variety of diagnostic tests, all of them aimed to detect structural and functional changes of the pancreas. Early in the disease course diagnosis is difficult, particularly when abdominal pain is the only symptom and the results of imaging tests are unequivocal [1]. In order to guide the clinician, several groups have attempted to design classifications and scorings systems for chronic pancreatitis $[1,2,3,4]$. For example, the M-ANNHEIM classification formulates criteria for definitive, probably and borderline chronic pancreatitis [5]. This classification also has components that allow patients to be categorized according to etiology, clinical stage, and severity of chronic pancreatitis.

Even when the diagnosis is established, a clear treatment protocol for chronic pancreatitis is lacking. Common opinion is that the treatment of chronic pancreatitis should be guided by the clinical presentation and specific complaints of the patient. A major issue is the lack of evidence for treatment paradigms. Nevertheless, several recommendations on therapy in chronic pancreatitis have been published $[6,7,8,9,10]$. In addition two recent guidelines have been published [11, 12]. In 2010 the Italian Association for the Study of the Pancreas published an Italian consensus regarding diagnosis and treatment in chronic pancreatitis. This consensus appraised the best available evidence combined with input from experts [11]. After a consensus meeting several statements on the diagnosis and treatment on chronic pancreatitis were made. 
The South African guidelines are based on best practice principles determined by the available evidence and the opinions of an expert group [12].

All in all, despite guidelines, important controversies concerning the diagnosis and treatment of chronic pancreatitis remain. Moreover, adherence to these guidelines is unclear. In an effort to revisit the most important issues, we developed a survey to evaluate current clinical practice in the Netherlands. The primary objective of this study was to evaluate decisions regarding the diagnosis, management and screening in chronic pancreatitis.

\section{METHODS}

\section{Vignette Survey Design}

We developed a vignette survey to evaluate decisions regarding essential aspects of the diagnosis and management of chronic pancreatitis aided by representative scenarios in chronic pancreatitis. The questionnaire included three clinical chronic pancreatitis cases (vignettes), followed by multiple-choice and open questions. The three vignettes were designed to evaluate controversies in the diagnosis, treatment and screening of chronic pancreatitis. The first clinical vignette assessed the use of diagnostic tests and the criteria to diagnose chronic pancreatitis. The second vignette assessed therapeutic decision making in chronic pancreatitis, regarding both medical and interventional therapies. The third vignette assessed aspects regarding screening and follow-up of hereditary pancreatitis. We developed the vignettes in cooperation with chronic pancreatitis experts of the Dutch Pancreatitis Study Group (www.pancreatitis.nl) and the Scientific Institute for Quality of Healthcare of our institution (http://www.iqhealthcare.nl). Each vignette included the patient's history, physical examination and results of relevant additional investigations (e.g., laboratory investigation, imaging or other diagnostic tests). This was followed by a number of questions pertaining to diagnostic testing, treatment and follow-up decisions. The full vignettes are presented in the supplementary file. Furthermore, the questionnaire included several questions regarding the clinical experience and the setting in which the physician provides care: type of hospital (academic vs. community), the number of chronic pancreatitis patients in their practice, and type of interventions performed, if any.

\section{Sampling Frame}

Three provider groups mainly involved in care for chronic pancreatitis patients in the Netherlands were surveyed: 1) gastroenterologists; 2) specialists internal medicine (internists); and 3) gastrointestinal surgeons. Additionally, we established an expert panel comprised of seven health professionals and leading researchers in the field of chronic pancreatitis as a fourth group (i.e., experts). Members of this panel were nonDutch physicians selected on the basis of demonstration of knowledge and competence documented by an extensive publication record on chronic pancreatitis. We surveyed all gastroenterologists registered as members of the Dutch Association of Specialists for Gastroenterology-Hepatology $(n=344)$. We also surveyed all internists registered as members of the Netherlands Association of Internal Medicine, working in a non-academic hospitals $(n=833)$. Furthermore, we surveyed gastrointestinal surgeons, registered as member of the Netherlands Society for Gastrointestinal Surgery $(n=422)$.

\section{Survey Distribution and Follow-up Procedures}

A request to participate in the survey was sent to the gastroenterologists and internists directly by e-mail, accompanying by a link to an online questionnaire platform. Nonresponders received two reminder e-mails. In the provider group of gastrointestinal 
surgeons, a request for participation was forwarded by the secretary of the Netherlands Society for Gastrointestinal Surgery.

\section{STATI STICS}

Results of all questions were analyzed separately and presented according to topic. Data are presented for the group of gastroenterologists, internists and gastrointestinal surgeons together and for the provider groups separately. We discuss differences of Dutch physicians and compare them to the strategies of non-Dutch experts. Statistical analysis was carried out by using the SPSS 18.0 for Windows. Frequencies of proposed diagnostic or treatment strategies for each vignette were calculated and compared among the three groups (gastroenterologists, internists, gastrointestinal surgeons) using the chi-square test (asymptotic $P$ values). When the expected values in any of the cells of a contingency table were below 5, the Fisher's exact test was used (exact $P$ values). We only performed a statistical analysis on diagnostic and therapeutical strategies of the gastroenterologists, internists and gastrointestinal surgeons. Statistical significance was defined as two-tailed $P$ values less than 0.05 . We discussed these outcomes in relation with the strategies of the experts.

\section{RESULTS}

\section{Sample Characteristics}

Table 1 displays the characteristics of the survey respondents. Requests for participation were sent to 1,599 physicians. 236 surveys sent to internists and gastroenterologists were returned because of incorrect addresses. Some 39 surveys were returned because the addressee did not treat chronic pancreatitis patients. One hundred ten physicians of the remaining 1,324 requests for participation sent returned their surveys (response percentage $8.3 \%)$. From the respondents, 34 of the responders were gastroenterologists $(30.9 \%), 43$ internists $(39.1 \%), 22$ gastrointestinal surgeons $(20.0 \%)$ and $11(10.0 \%)$ respondents 'other' (e.g., 5 intensivists, 1 nephrologist, and 5 not reported) (Table 1 ). The mean age of respondents was 47 years (range: 33-66 years). The majority of physicians provided care in a non-academic hospital $(63 / 105,60.0 \%)$ and had a clinical experience of 10-20 years (gastroenterologists 20/33, 60.6\%; gastrointestinal surgeons: $13 / 22,59.1 \%$ ) or more than 20 years (internists $28 / 43,65.1 \%$ ).

Seventy-three (71.6\%) out of 102 respondents provided care for chronic pancreatitis patients. Most indicated that they treat chronic pancreatitis patients themselves, and only a minority $(n=29,28.4 \%)$ referred patients to specialized centers on a regular basis. $A$ total of $12(35.3 \%)$ responding gastroenterologists also indicated to perform endoscopic ultrasonography (EUS)-guided drainage of pancreatic fluid collections and $16(47.1 \%)$ of the gastroenterologists performed endoscopic intervention in chronic pancreatitis patients. Fourteen $(63.6 \%)$ of all responding surgeons indicated that they did operate on chronic pancreatitis patients.

Table 1. Characteristics of the respondents.

\begin{tabular}{cccc}
\hline & $\begin{array}{c}\text { Gastroenterologists } \\
(\mathbf{n}=\mathbf{3 4})\end{array}$ & $\begin{array}{c}\text { Internists } \\
(\mathbf{n}=\mathbf{4 3})\end{array}$ & $\begin{array}{c}\text { Gastrointestina } \\
\text { surgeons (n=22 }\end{array}$ \\
\hline $\begin{array}{c}\text { Practice: } \\
- \text { Academic hospital }\end{array}$ & $3(8.8 \%)$ & 0 & $7(31.8 \%)$
\end{tabular}


- Non-academic teaching hospital

- Non-academic non-teaching hospital

Number of valid responses

\section{Years in practice:}

$$
\text { - } 0 \text { - } 10 \text { years }
$$$$
\text { - 10-20 years }
$$

- More than 20 years

Number of valid responses

$$
\begin{gathered}
23(67.6 \%) \\
8(23.5 \%) \\
34
\end{gathered}
$$

$$
\begin{gathered}
4(12.1 \%) \\
20(60.6 \%) \\
9(27.3 \%)
\end{gathered}
$$

33

Number of chronic pancreatitis patients seen (yearly):

$-0-10$
$-10-30$
- More than 30
Number of valid responses
$17(51.5 \%)$
$14(42.4 \%)$
$2(6.1 \%)$

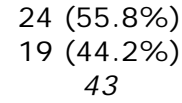

$5(11.6 \%)$

$10(23.3 \%)$

$28(65.1 \%)$

43

$37(88.1 \%)$
$4(9.5 \%)$
$1(2.4 \%)$

42
$11(50.0 \%)$

4 (18.2\%)

22

$1(4.5 \%)$

$13(59.1 \%)$

$8(36.4 \%)$

22

$15(68.2 \%)$

$4(18.2 \%)$

$3(13.6 \%)$

\footnotetext{
a Other: 5 intensivists, 1 nephrologist, and 5 not reported
}

\section{Diagnosis}

We presented a typical case of chronic pancreatitis with continuous abdominal pain and frequent exacerbations and asked which laboratory test is an important part of the diagnostics. The most common test used was fecal elastase (54/110, 49.1\%). Fecal elastase was most often chosen by gastroenterologists $(25 / 34,73.5 \%)$ and by experts in $71.4 \%(5 / 7)$. On the other hand, amylase was considered as a diagnostic tool in chronic pancreatitis by $42.9 \%(3 / 7)$ of experts, compared to $38.2 \%(13 / 34)$ of the gastroenterologists, $27.3 \%(6 / 22)$ of the gastrointestinal surgeons and $72.1 \%(31 / 43)$ of the internists (Figure 1). When subsequently asked which imaging modality was used first at suspicion of chronic pancreatitis, only a minority $(22 / 91,24.2 \%)$ of all respondents considered transabdominal ultrasonography as useful in diagnosing chronic pancreatitis, compared to $71.4 \%(5 / 7)$ experts (Figure 2). The majority of the respondents $(63 / 91,69.2 \%)$ indicated they used CT instead as the confirmatory test, whereas only 2 out of $7(28.6 \%)$ experts would perform a CT in this case. 


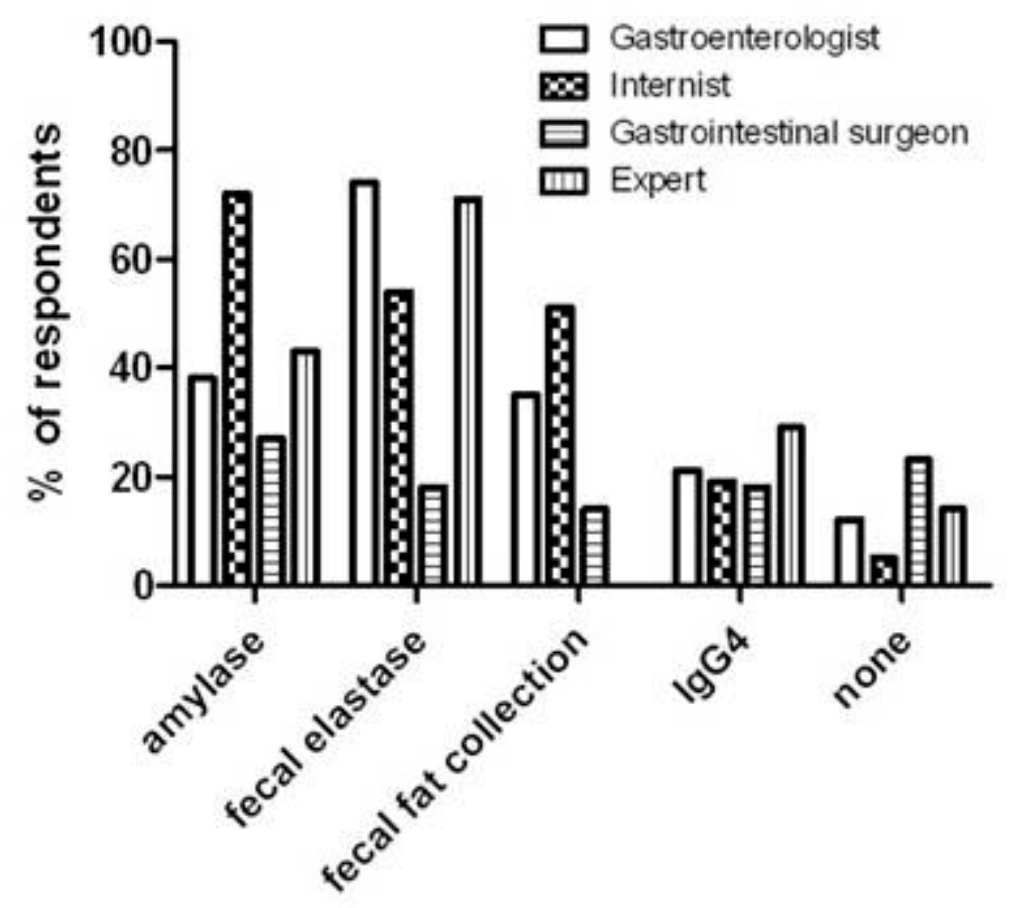

Figure 1. Diagnostic strategies are questioned in a clinical vignette. In this case, we ask the physicians which laboratory test plays an important part of their diagnostics.

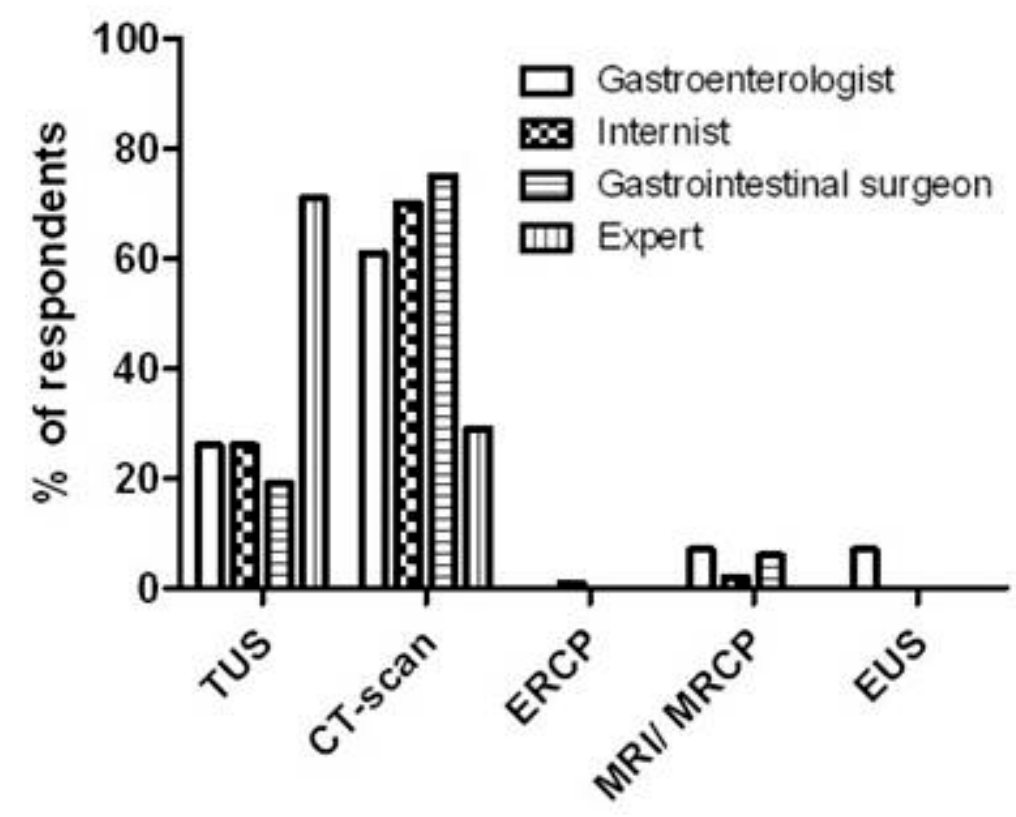

Figure 2. In a clinical vignette, the respondents were asked which radiological modality they prefer first diagnostic tool in considering chronic pancreatitis in a patient.

TUS: transabdominal ultrasonography

EUS: endoscopic ultrasonography 
Regarding the criteria for establishing chronic pancreatitis, we noted large differences between the different categories of respondents (Table 2). Some $73.8 \%(62 / 84)$ of the respondents and all 7 experts diagnosed chronic pancreatitis in case of chronic abdominal pain and calcifications on a plain abdominal X-ray. In case of relapsing pseudocysts $78.8 \%(67 / 85)$ of all respondents regarded this as indicative for chronic pancreatitis compared to $71.4 \%(5 / 7)$ experts. Five out of $12(41.7 \%)$ of the gastrointestinal surgeons and $32.4 \%(12 / 37)$ of the internists diagnosed chronic pancreatitis in case of chronic abdominal pain and elevated amylase, compared to only $6.7 \%(2 / 30)$ of the gastroenterologists $(P=0.009)$.

Regarding etiology, $46.1 \%(41 / 89)$ of the respondents considered alcohol as a cause of chronic pancreatitis at consumption of 4 or more standard drinks/day for men and 3 or more standard drinks/day for women during more than 6 months (by considering $12 \mathrm{~g}$ ethanol in each drink).

Table 2. When do you diagnose chronic pancreatitis?

\begin{tabular}{|c|c|c|c|c|}
\hline & $\begin{array}{c}\text { Overall } \\
(n=110)^{a}\end{array}$ & $\begin{array}{c}\text { Gastroenterologists } \\
(\mathrm{n}=\mathbf{3 4 )}\end{array}$ & $\begin{array}{c}\text { I nternists } \\
(n=43)\end{array}$ & $\begin{array}{l}\text { Gastrointestinal } \\
\text { surgeons }(n=22)\end{array}$ \\
\hline $\begin{array}{c}\text { Chronic "typical" abdominal pain without } \\
\text { alternative diagnosis }\end{array}$ & $\begin{array}{l}6 / 80 \\
(7.5 \%)\end{array}$ & $\begin{array}{l}1 / 30 \\
(3.3 \%)\end{array}$ & $\begin{array}{c}3 / 37 \\
(8.1 \%)\end{array}$ & $\begin{array}{c}1 / 11 \\
(9.1 \%)\end{array}$ \\
\hline $\begin{array}{l}\text { Chronic abdominal pain and elevated } \\
\text { amylase }\end{array}$ & $\begin{array}{c}20 / 81 \\
(24.7 \%)\end{array}$ & $\begin{array}{l}2 / 30 \\
(6.7 \%)\end{array}$ & $\begin{array}{c}12 / 37 \\
(32.4 \%)\end{array}$ & $\begin{array}{c}5 / 12 \\
(41.7 \%)\end{array}$ \\
\hline $\begin{array}{c}\text { Chronic abdominal pain and calcifications } \\
\text { on abdominal X-ray }\end{array}$ & $\begin{array}{c}62 / 84 \\
(73.8 \%)\end{array}$ & $\begin{array}{c}25 / 31 \\
(80.6 \%)\end{array}$ & $\begin{array}{c}29 / 39 \\
(74.4 \%)\end{array}$ & $\begin{array}{c}6 / 12 \\
(50.0 \%)\end{array}$ \\
\hline $\begin{array}{l}\text { Chronic abdominal pain and first } \\
\text { complaints of steatorrhea }\end{array}$ & $\begin{array}{c}33 / 79 \\
(41.8 \%)\end{array}$ & $\begin{array}{c}12 / 30 \\
(40.0 \%)\end{array}$ & $\begin{array}{c}15 / 36 \\
(41.7 \%)\end{array}$ & $\begin{array}{c}5 / 11 \\
(45.5 \%)\end{array}$ \\
\hline $\begin{array}{l}\text { Steatorrhea, improving with pancreatic } \\
\text { enzyme supplementation }\end{array}$ & $\begin{array}{c}47 / 81 \\
(58.0 \%)\end{array}$ & $\begin{array}{c}17 / 30 \\
(56.7 \%)\end{array}$ & $\begin{array}{c}22 / 37 \\
(59.5 \%)\end{array}$ & $\begin{array}{c}7 / 12 \\
(58.3 \%)\end{array}$ \\
\hline Decreased fecal elastase & $\begin{array}{c}32 / 79 \\
(40.5 \%)\end{array}$ & $\begin{array}{c}14 / 30 \\
(46.7 \%)\end{array}$ & $\begin{array}{c}12 / 36 \\
(33.3 \%)\end{array}$ & $\begin{array}{c}4 / 11 \\
(36.4 \%)\end{array}$ \\
\hline Relapsing pseudocysts & $\begin{array}{c}67 / 85 \\
(78.8 \%)\end{array}$ & $\begin{array}{c}22 / 31 \\
(71.0 \%)\end{array}$ & $\begin{array}{c}33 / 40 \\
(82.5 \%)\end{array}$ & $\begin{array}{c}11 / 12 \\
(91.7 \%)\end{array}$ \\
\hline Dilated pancreatic duct & $\begin{array}{c}33 / 81 \\
(40.7 \%)\end{array}$ & $\begin{array}{c}9 / 29 \\
(31.0 \%)\end{array}$ & $\begin{array}{c}16 / 38 \\
(42.1 \%)\end{array}$ & $\begin{array}{c}7 / 12 \\
(58.3 \%)\end{array}$ \\
\hline
\end{tabular}

Willingness to diagnose chronic pancreatitis on the basis of symptoms and/or result of a diagnostic test in a chronic pan respondents were asked: 'When do you diagnose chronic pancreatitis? Choose yes or no if you consider this as sufficient pancreatitis'. The reported percentages represent the percentage of respondents who answered this question on diagno excluded).

Overall: a total of gastroenterologists, internists and gastrointestinal surgeons

a The 11 respondents other than gastroenterologists, internists and gastrointestinal surgeons are also included

${ }^{\mathrm{b}}$ The difference among the gastroenterologists, internists and gastrointestinal surgeons is calculated

\section{Medical Treatment of Pain}


In general, all of the 34 gastroenterologists indicated that they prescribe pancreatic enzymes for chronic pancreatitis, compared to $86.0 \%(37 / 43)$ of the internists and $40.9 \%(9 / 22)$ of the gastrointestinal surgeons $(\mathrm{P}<0.001)$. When a patient with uncomplicated chronic pancreatitis presents with daily abdominal pain using only acetaminophen and non-steroidal anti-inflammatory agents (NSAIDs), pancreatic enzymes were prescribed as subsequent treatment for pain by half of the respondents: $58.8 \%(20 / 34)$ of the gastroenterologists, $55.8 \%(24 / 43)$ of the internists and $27.3 \%$ $(6 / 22)$ of the gastrointestinal surgeons $(P=0.046)$. This contrasts with the experts where only 1 out of 7 experts (14.3\%) would do so.

A large majority of the respondents prescribed analgesics. When asked about type of analgesics commonly prescribed for chronic pancreatitis patients, $42.7 \%(47 / 110)$ indicated to use acetaminophen and 26.4\% (29/110) used NSAIDs. Different morphine derivates were prescribed in a frequency ranging between 6.4 and $50.9 \%$ of the 110 respondents: buprenorphine in $6.4 \%(n=7)$, morphine sulfate in $11.8 \%(n=13)$, fentanyl in $28.2 \%(n=31)$, oxycodon in $35.5 \%(n=39)$ and tramadol in $50.9 \%(n=56)$. Only few indicated the use of pregabalin $(5 / 110,4.5 \%)$ for chronic pancreatitis. Analgesics usually were advised on continuous basis $(73 / 110,66.4 \%$ of the respondents) rather than on demand.

\section{Treatment of Pancreatic Exocrine and Endocrine Insufficiency}

Fifty percent of the respondents $(42 / 84)$ indicated that in case of exocrine insufficiency their preferred initial dose of pancreatic enzymes would be 25,000 units of lipase per meal and 10,000 units of lipase with snacks. A higher initial dose $(50,000$ units of lipase per meal and 25.000 units of lipase with snacks) was more frequently (although not significantly, $\mathrm{P}=0.701)$ prescribed by experts $(3 / 7,42.9 \%)$ compared to the respondents $(30 / 84,35.7 \%)$. Diabetes secondary to chronic pancreatitis was treated only by internists $(38 / 43,88.4 \%)$.

\section{I nterventional Treatment}

In case of persistent pain in a chronic pancreatitis patient, respondents but also experts had a low threshold for interventional treatment (Table 3). All 79 respondents and 7 experts advised to perform an intervention in case of morphological changes of the pancreatic duct (e.g., dilation of pancreatic duct, intraductal stones). Endoscopic treatment (lithotripsy and stenting of the pancreatic duct in case of stenosis) was preferred by internists $(31 / 36,86.1 \%)$ and 4 out of 7 experts (57.1\%). Surgical treatment (pancreaticojejunostomy) was preferred by gastroenterologists (15/29, $51.7 \%)$, gastrointestinal surgeons $(8 / 12,66.7 \%)$ and 2 out of 7 experts $(28.6 \%)$. On the other hand, internists rarely referred for surgery in this case $(5 / 36,13.9 \% ; P<0.001$ among gastroenterologists, gastrointestinal surgeons and internists). In case of a chronic pancreatitis patient with ongoing pain despite narcotics, but without dilated pancreatic duct or duct stones, still $22.2 \%(18 / 81)$ of the respondents and one out of 7 experts (14.3\%) considered endoscopic treatment. A majority of the experts $(4 / 7,57.1 \%)$ considered surgery, as would $9.9 \%(8 / 81)$ of the respondents. Few respondents $(13 / 81$, $16.0 \%)$ considered a thoracoscopic splanchnicectomy $(P=0.097$ among gastroenterologists, gastrointestinal surgeons and internists).

Table 3. Clinical vignette: Interventional treatment in chronic pancreatitis. (We present a patient with idiopathic chronic abdominal pain despite analgesic use, including opioids. We ask the respondents which additional treatment they consider in tw and without pancreatic duct dilation). 


\begin{tabular}{|c|c|c|c|c|}
\hline $\begin{array}{l}\text { Which additional treatment do you consider at this } \\
\text { moment? }\end{array}$ & $\begin{array}{c}\text { Overall } \\
(n=110)\end{array}$ & $\begin{array}{c}\text { Gastroenterologists } \\
(n=34)\end{array}$ & $\begin{array}{c}\text { I nternists } \\
(n=43)\end{array}$ & $\begin{array}{l}\text { Gastro } \\
\text { surgeo }\end{array}$ \\
\hline $\begin{array}{c}\text { In case of no dilated pancreatic duct }(\mathbf{P}=\mathbf{0 . 0 9 7} \mathbf{b}) \text { : } \\
\text { - Continue narcotics in a higher dose } \\
\text { - Thoracoscopic splanchnicectomy } \\
\text { - Enteral feeding (jejunal tube) } \\
\text { - Endoscopic therapy } \\
\text { - Surgical treatment } \\
\text { Number of valid responses }\end{array}$ & $\begin{aligned} & 37(45.7 \%) \\
& 13(16.0 \%) \\
& 5(6.2 \%) \\
& 18(22.2 \%) \\
& 8(9.9 \%) \\
& 81\end{aligned}$ & $\begin{array}{c}14(48.3 \%) \\
6(20.7 \%) \\
2(6.9 \%) \\
3(10.3 \%) \\
4(13.8 \%) \\
29\end{array}$ & $\begin{array}{c}15(40.5 \%) \\
5(13.5 \%) \\
2(5.5 \%) \\
14(37.8 \%) \\
1(2.7 \%) \\
37\end{array}$ & $\begin{array}{l}6( \\
2( \\
1) \\
1( \\
31\end{array}$ \\
\hline $\begin{array}{l}\text { In case of dilated pancreatic duct with intraductal } \\
\text { stones }(\mathbf{P}<\mathbf{0 . 0 0 1} \mathbf{b}) \text { : } \\
\text { - Endoscopic treatment; lithotripsy and stenting of the } \\
\text { pancreatic duct in case of stenosis }\end{array}$ & $50(63.3 \%)$ & $13(44.8 \%)$ & $31(86.1 \%)$ & \\
\hline $\begin{array}{l}\text { - Thoracoscopic splanchnicectomy } \\
\text { - Surgical treatment: pancreaticojejunostomy (Partington- } \\
\text { Rochelle) }\end{array}$ & $\begin{array}{c}1(1.3 \%) \\
28(35.4 \%)\end{array}$ & $\begin{aligned} 1 & (3.4 \%) \\
15 & (51.7 \%)\end{aligned}$ & $\begin{array}{c}0 \\
5(13.9 \%)\end{array}$ & \\
\hline $\begin{array}{c}\text { - I do not consider additional treatment at the moment } \\
\text { Number of valid responses }\end{array}$ & $\begin{array}{c}0 \\
79\end{array}$ & $\begin{array}{c}0 \\
29\end{array}$ & $\begin{array}{c}0 \\
36 \\
\end{array}$ & \\
\hline
\end{tabular}

Overall: a total of gastroenterologists, internists and gastrointestinal surgeons

${ }^{a}$ The 11 respondents other than gastroenterologists, internists and gastrointestinal surgeons are also included

${ }^{\mathrm{b}}$ Gastroenterologists, internists and gastrointestinal surgeons were compared

Furthermore, respondents differed in their timing of additional treatment (endoscopic or surgical treatment). Even in case of a chronic pancreatitis patient with a dilated pancreatic duct and stones, $29.6 \%(24 / 81)$ of the respondents only considered additional treatment if the patient still experiences pain (despite a maximum dose of narcotics). On the other hand, $70.4 \%(57 / 81)$ also considered additional treatment in this case if there is adequate pain relief ( with a maximum dose of narcotics).

\section{Screening for Pancreatic Cancer}

Some $62.3 \%$ (37 out of the 59 respondents) recommended that patients with hereditary pancreatitis should enter a screening program for pancreatic adenocarcinoma. The majority of the respondents $(n=19,32.2 \%)$ would use EUS as screening modality, as would $2 / 7$ experts $(28.6 \%)$. Twenty-five percent of the respondents $(n=15)$ would use CT-scanning in screening, unlike any of the 7 experts. Screening was performed annually or biannually, according to the respondents. Only $5.1 \%(n=3)$ of the respondents used MRCP for screening purposes. Screening of young relatives of hereditary pancreatitis patients did not yield wide support. In such cases, $84.7 \%(61 / 72)$ of the respondents $(25 / 30,83.3 \%$ of the gastroenterologists; $26 / 29,89.7 \%$ of the internists; $9 / 11,81.8 \%$ of the gastrointestinal surgeons; and one out of the two other respondents) would first refer relatives of hereditary pancreatitis patients to a department of clinical genetics for consultation. In order to decrease the risk of pancreatic carcinoma, a large majority of the respondents strongly advised cessation of alcohol consumption and cigarette smoking.

\section{DISCUSSION}

The results of our survey display the discordance between physicians when it comes to diagnosis, treatment, and follow-up of chronic pancreatitis. The discordance is present between different specialties that treat and care for chronic pancreatitis patients, but also 
among experts. This is not an unexpected result as diagnosis and treatment of these patients is difficult. Moreover, there is a paucity of evidence in this field and the large variation in answers by physicians involved in chronic pancreatitis care reflects this. We focused on three major components of chronic pancreatitis; diagnostics, management and screening.

When it comes to laboratory test for diagnosing chronic pancreatitis, amylase was used frequently by internists, while gastroenterologists and experts often use fecal elastase as a diagnostic tool. Fecal elastase-1 test has a high predictive value for pancreatic insufficiency, but test lacks sensitivity for mild to moderate pancreatic exocrine insufficiency [12, 13]. A majority of the chronic pancreatitis experts considered transabdominal US as useful diagnostic imaging technique to confirm the clinical suspicion of chronic pancreatitis. In the recently published South African guidelines, transabdominal US is considered to carry limited value because of lack of sensitivity and specificity [12]. The Italian guidelines promote transabdominal US in confirming the diagnosis of advanced chronic pancreatitis, since it identifies gross abnormalities of the pancreas, e.g., dilatation of the pancreatic duct [11]. However, the main value of transabdominal US is the ability to differentiate chronic pancreatitis from other causes of abdominal pain.

CT, MRCP and increasingly EUS emerge from our survey as tools to confirm the diagnosis, in concordance with the guidelines. The choice of diagnostic modality depends on the reported sensitivity and specificity, but also on the local availability and available skills. In addition, the diagnostic accuracy depends on the stage of disease. MRI can be used for the assessment of chronic pancreatitis to evaluate both parenchymal and ductal changes [14]. MRCP-secretin is able to detect side-branch ecstasies and can yield functional information of the pancreas [15]. CT has a high sensitivity and specificity and is frequently used as the screening test of choice. CT can show multiple aspects of chronic pancreatitis such as gland atrophy, dilation of the main pancreatic duct and pancreatic stones. However, these signs are typically restricted to advanced chronic pancreatitis. EUS on the other hand is increasingly being used to diagnose chronic pancreatitis and has proven ability to assess changes of the pancreatic parenchyma. On the other hand, the inter-observer variability is great, in particular in cases with so called "early" chronic pancreatitis.

In the treatment of pain in uncomplicated chronic pancreatitis, respondents of this survey frequently use pancreatic enzymes. This is surprisingly since evidence for this strategy is absent. There have been several small randomized placebo-controlled trials assessing the ability of pancreatic enzymes to reduce pain. Two small studies using non-enteric-coated enzymes demonstrated a reduction in pain, while three other studies using entericcoated preparations showed no improvement in pain. A meta-analysis and a Cochrane review corroborated that enzymes are ineffective for pain [16, 17]. However, the South African guidelines advise a 6-week trial of high-dose pancreatic enzymes (in uncoated tablet form) in patients who fail to acetaminophen or NSAIDs which contrasts with the I talian guidelines [12]. All respondents of this survey use non-narcotic episodic analgesia and narcotic analgesia for pain relief. Few use pregabalin, as well as 2 of the 7 experts. The use of pregabalin is supported by the positive outcome of a recent randomized clinical trial, where it relieved chronic pancreatitis pain after 3 weeks of treatment [18].

In the area of interventional treatment, there are more controversies. In case of a chronic pancreatitis patient with pain despite narcotics but no morphological changes of the pancreas, $22 \%$ of the respondents and one expert still considered endoscopic treatment. Surprisingly, a majority of the experts $(4 / 7 ; 57 \%)$ considered surgery, compared to $10 \%$ of the respondents. Both guidelines stipulate that interventional procedures should be reserved for symptomatic patients. There are no robust data that favor use of interventional therapy in asymptomatic patient with pancreatic duct dilatation. However, the Italian guidelines suggest that surgical decompression of the main pancreatic duct may be considered in patients with asymptomatic chronic 
pancreatitis and ductal dilation (greater than $7 \mathrm{~mm}$ ) to prevent the progression of exocrine and endocrine insufficiency, but evidence is lacking [11].

Nonetheless, interventional procedures are either directed at addressing the morphological changes of the pancreatic duct system (strictures and stones), and inflammatory changes of the parenchyma, or by neurolysis of its nerve supply. This is clearly an area of uncertainty as studies in experimental obstructive pancreatitis, show that early drainage leads to improvement of and recovery of histological changes [19]. If there is an indication for an interventional treatment, responders of this survey have a different strategy regarding endoscopic or surgical treatment. In case of main pancreatic duct dilation, guidelines advice endoscopic treatment as a reasonable first option, because of the less invasive nature of this treatment [12]. A recent study showed that after 5-year follow-up, symptomatic patients with advanced chronic pancreatitis who underwent surgery as the initial treatment for pancreatic duct obstruction had more pain relief with fewer procedures, than patients who were treated endoscopically [20]. Moreover, almost half of the patients who were treated with endoscopy eventually underwent surgery. This suggests that the advice of endoscopic treatment in case of pancreatic duct dilation in patients with advanced disease is at odds with the available evidence. In case of early disease, there might be a role for endoscopic therapy but this requires further investigation.

Furthermore, there are important controversies on the timing of interventional treatment; early in disease course or only in complicated disease. Previously, interventional treatment was only considered in case of pain despite narcotics. Nowadays, more frequently interventional treatment is advised in case of a failure of non-narcotic analgesia to avoid narcotic addiction. Moreover, this may lead to a better recovery of histological changes and pancreatic exocrine function [19]. Currently, there is ongoing research about timing of surgery in painful chronic pancreatitis.

A total of some $62 \%$ of the respondents of our survey recommend screening for pancreatic carcinoma in hereditary pancreatitis patients with EUS or CT, annually or biannually. Chronic pancreatitis is known risk factor for pancreatic adenocarcinoma [21]. The risk is most prominent in hereditary pancreatitis. Patients with hereditary pancreatitis run a cumulative risks of pancreatic cancer up to $53.5 \%$ at 75 years of age [22]. However, routine screening of all forms of chronic pancreatitis for adenocarcinoma is not currently recommended [12]. Some advice screening for pancreatic adenocarcinoma [22]. Yet, there is no generally accepted protocol for screening chronic pancreatitis patients for early pancreatic cancer [23]. In recommendations for surveillance on pancreatic cancer in general usually no recommendations for patients on hereditary pancreatitis are proposed. A recent narrative review recommends yearly screening preferably in a referral center starting at the age of 40 [22]. MRI and CT are preferred as method of screening, despite lack of data. In case of absence of multiple calcifications, an EUS can be performed. When there is advanced hereditary pancreatitis, the diagnostic value of EUS is limited because fibrosis the early detection of lesion. The recommendations posed in the South African guidelines correspond with this review [12, 22].

\section{MI TATI ONS}

This study has limitations. There is a limited response rate. We do not know the specific reasons why non-responders declined participation. This may be partly due to the limited number of physicians involved in the care for chronic pancreatitis patients. In the Netherlands there are about 100 hospitals in which only a few specialists in every hospital treats chronic pancreatitis patients. Together they treat approximately 1,000 new chronic pancreatitis patients every year (www.pancreatitis. $n$ l). Thus, a large majority of gastroenterologists, internists and gastrointestinal surgeons sees few or even no chronic pancreatitis patients. Therefore, the 110 included physicians represent a significant part of the total group of specialist managing chronic pancreatitis in the Netherlands. Interestingly, a relatively large proportion of the responding physicians 
indicate that they perform interventional procedures in chronic pancreatitis (EUS-guided drainage of pancreatic fluid collections and surgery in chronic pancreatitis). This may reflect an increased interest in chronic pancreatitis by responders of the survey and suggest that respondents are knowledgeable of the published literature.

In conclusion, our study documents the presence of heterogeneity in diagnostic and therapeutic strategies probably reflecting the lack of evidence in this field (Table 4).

Table 4. Main controversies from this survey.

- Overall variation in the diagnostic and therapeutic decision-making process in clinical practice

- Different strategies in the diagnoses of chronic pancreatitis between internists and gastroenterologists, and experts on the ot

- Treatment with pancreatic enzymes frequently used in management of pain in chronic pancreatitis despite of lack of evidence

- A wide variation in timing of interventional procedures in uncomplicated chronic pancreatitis

- Different opinions on screening for pancreatic cancer in hereditary pancreatitis.

This paper also illustrates the need for continuing education regarding the diagnosis and treatment of chronic pancreatitis, since wide adopted practices are not in line with current evidence. Considering the high number of physicians in non-academic centers and small hospitals, centralization of the care for chronic pancreatitis might increase uniformity and also improve the level of care for this complex disease.

APPENDIX (supplementary file): survey of the treatment of chronic pancreatitis.

Received January $27^{\text {th }}, 2012$ - Accepted March $8^{\text {th }}, 2012$

Key words Data Collection; Diagnosis; Pancreatitis, Chronic; Therapeutics

Abbreviations NSAIDs: non-steroidal anti-inflammatory agents

Conflict of interest The authors have no potential conflict of interest

\author{
Correspondence \\ Aura AJ van Esch \\ Department of Gastroenterology and Hepatology \\ Radboud University Nijmegen Medical Center \\ P.O. Box 9101 (internal code MDL 455) \\ 6500 HB Nijmegen \\ The Netherlands \\ Phone: +31 243614760 \\ Fax +31 243540103 \\ E-mail: a.vanesch@mdl.umcn.nl
}




\section{References}

1. Banks PA. Classification and diagnosis of chronic pancreatitis. J Gastroenterol 2007 January; 42 Suppl 17: 148-51.

2. Buchler MW, Martignoni ME, Friess H, Malfertheiner P. A proposal for a new clinical classification of chronic pancreatitis. BMC Gastroenterol 2009; 9:93.

3. Keith RG. Definition and classification of chronic pancreatitis. World J Surg 2003 November;27(11): 1172-4.

4. Ramesh H. Proposal for a new grading system for chronic pancreatitis: the ABC system. J Clin Gastroenterol 2002 July; 35(1):67-70.

5. Schneider A, Lohr JM, Singer MV. The M-ANNHEIM classification of chronic pancreatitis: introduction of a unifying classification system based on a review of previous classifications of the disease. J Gastroenterol 2007 February; 42(2): 101-19.

6. Warshaw AL, Banks PA, Fernandez-Del CC. AGA technical review: treatment of pain in chronic pancreatitis. Gastroenterology 1998 September; 115(3): 765-76.

7. Tandon RK, Sato N, Garg PK. Chronic pancreatitis: Asia-Pacific consensus report. J Gastroenterol Hepatol 2002 April; 17(4):508-18.

8. Tringali A, Boskoski I, Costamagna G. The role of endoscopy in the therapy of chronic pancreatitis. Best Pract Res Clin Gastroenterol 2008; 22(1): 145-65.

9. Meier RF, Beglinger C. Nutrition in pancreatic diseases. Best Pract Res Clin Gastroenterol 2006;20(3):50729.

10. Pancreas Study Group CSoG. Guidelines for the diagnosis and treatment of chronic pancreatitis (Nanjing, 2005). Chin J Dig Dis 2005;6(4): 198-201.

11. Frulloni L, Falconi M, Gabbrielli A, Gaia E, Graziani R, Pezzilli R et al. Italian consensus guidelines for chronic pancreatitis. Dig Liver Dis 2010 November; 42 Suppl 6:S381-S406.

12. Bornman PC, Botha JF, Ramos JM, Smith MD, Van der Merwe S, Watermeyer GA et al. Guideline for the diagnosis and treatment of chronic pancreatitis. S Afr Med J 2010 December; 100(12 Pt 2):845-60.

13. Tod J, Fine D. Fecal elastase: a useful test for pancreatic insufficiency? Dig Dis Sci 2010 October; 55(10): 2709-11.

14. Balci C. MRI assessment of chronic pancreatitis. Diagn Interv Radiol 2011 September; 17(3):249-54.

15. Sandrasegaran K, Lin C, Akisik FM, Tann M. State-of-the-art pancreatic MRI. AJR Am J Roentgenol 2010 July; $195(1): 42-53$

16. Shafiq N, Rana S, Bhasin D, Pandhi P, Srivastava P, Sehmby SS et al. Pancreatic enzymes for chronic pancreatitis. Cochrane Database Syst Rev 2009; (4):CD006302.

17. Winstead NS, Wilcox CM. Clinical trials of pancreatic enzyme replacement for painful chronic pancreatitis-a review. Pancreatology 2009;9(4):344-50.

18. Olesen SS, Bouwense SA, Wilder-Smith $\mathrm{OH}$, van Goor GH, Drewes AM. Pregabalin reduces pain in patients with chronic pancreatitis in a randomized, controlled trial. Gastroenterology 2011 August; 141(2):536-43.

19. Lamme B, Boermeester MA, Straatsburg IH, van Buijtenen JM, Boerma D, Offerhaus GJ et al. Early versus late surgical drainage for obstructive pancreatitis in an experimental model. Br J Surg 2007 July; 94(7):849-54.

20. Cahen DL, Gouma DJ, Laramee P, Nio Y, Rauws EA, Boermeester MA et al. Long-term outcomes of endoscopic vs. surgical drainage of the pancreatic duct in patients with chronic pancreatitis. Gastroenterology 2011 November; 141(5): 1690-5.

21. Bansal P, Sonnenberg A. Pancreatitis is a risk factor for pancreatic cancer. Gastroenterology 1995 July; 109(1):247-51.

22. Rebours V, Levy P, Ruszniewski P. An overview of hereditary pancreatitis. Dig Liver Dis 2012 January; 44(1): 8-15.

23. Rosendahl J, Bodeker H, Mossner J, Teich N. Hereditary chronic pancreatitis. Orphanet J Rare Dis 2007;2:1. 